\title{
ANALISIS KEBUTUHAN DAN MANAJEMEN PEMELIHARAAN ELEVATOR GEDUNG KEMENTRIAN DALAM NEGERI REPUBLIK INDONESIA
}

\author{
Nadia UtamiNishar ${ }^{1}$, Andi Tenrisukki $\mathbf{T}^{2)}$ \\ ${ }^{1)}$ Magister Teknik Sipil, Program Pascasarjana, Universitas Gunadarma \\ ${ }^{2)}$ Program Studi Teknik Sipil, Universitas Gunadarma \\ Jl. Margonda Raya No.100, Depok, Jawa Barat \\ Email:nadiautaminishar@yahoo.co.id ${ }^{1)}$,andi_t@@staff.gunadarma.ac.id ${ }^{2)}$
}

DOI: http://dx.doi.org/10.29103/tj.v11i1.415

(Received: December 2020 / Revised: January 2021 / Accepted: January 2021)

\begin{abstract}
Abstrak
Penelitian ini bertujuan untuk mengetahui jumlah elevator di gedung Badan Pengembangan Sumber Daya Manusia Jakarta Kementerian Dalam Negeri, daya elevator, dan anggaran yang dibutuhkan untuk pemeliharaan elevator. Metode pengumpulan data yang digunakan dalam penelitian ini adalah dengan mengamati secara langsung data utama yang diperoleh dari pengguna elevator pada jam sibuk. Data pelengkap diperoleh dari wawancara dan dokumen. Metode analisis data menggunakan analisis jumlah penghuni gedung, analisis beban puncak, analisis waktu tunggu, analisis waktu pulang pergi, analisis jumlah elevator, dan metode preventif untuk pemeliharaan elevator. Hasil penelitian menunjukkan bahwa kebutuhan elevator paling banyak 4, konsumsi listrik dalam waktu 10 jam adalah $34 \mathrm{kWh}$, dan metode perawatan preventif akan mempengaruhi kinerja mesin elevator.
\end{abstract}

Kata Kunci: jumlah elevator, perawatan, dayalistrik

\begin{abstract}
This study aims to determine the number of needs for elevators, elevator electric power, and the budget needed for elevator maintenance at the Ministry of Internal Affairs, Jakarta Human Resources Development Agency Building. The data collection method used in this research is primary data obtained from direct observation of elevator users during busy hours. Secondary data obtained from interviews and documentation. The data analysis method uses analysis of the number of building occupants, peak load analysis, waiting time analysis, round trip time analysis, number of elevators analysis, and preventive methods for elevator maintenance. The results showed that the need for elevators as many as 4 units with electricity needs of $34 \mathrm{kwh}$ in 10 hours and preventive maintenance methods can affect the performance of the machine in the elevator.
\end{abstract}

Keywords: number of elevators, maintenance, electric power

\section{Latar Belakang}

Elevator/lift ialah alat transportasi vertikal yang digunakan sebagai alat untuk mempromosikan kegiatan pembangunan bertingkat. Bisa jadi alternatif pengganti tangga untuk mencapai setiap lantai.(Moch, Balai and Semarang, 2014) 
Transportasi vertikal digunakan untuk mengangkut benda dari bawah ke atas, atau merupakan suatu metode transportasi yang dirancang untuk memenuhi kebutuhan penghuni guna menunjang aktivitas pada gedung bertingkat. Transportasi vertikal meliputi elevator (elevator), eskalator, ramp, tangga, elevator barang (Dumb waiter) dan traktor (konveyor). Elevator adalah suatu metode transportasi yang mengangkut barang atau penumpang dari satu lantai ke lantai lain. Untuk itu dibutuhkan suatu moda transportasi. Dalam setiap elevator, perencanaan harus dilakukan dengan syarat perencanaan yang baik.(Samsudin, 2013)

Jumlah elevator yang cukup untuk transportasi vertikal merupakan faktor penting karena mempengaruhi kualitas pelayanan gedung, sehingga diperlukan manajemen pemeliharaan yang dapat mengatur kinerja elevator.(Frick and Setiawan, 2002). Dapat mengelola pemeliharaan kinerja elevator bisa jadi manajemen pemeliharaan elevator yang baik meliputi pemeliharaan rutin, pemeriksaan komponen, penggantian komponen yang perlu diganti, dan perkiraan biaya pemeliharaan yang perlu dikeluarkan administrator gedung setiap tahunnya.(Afifahet al., 2017)

Pilihan penggunaan elevator bergantung pada arus orang di dalam gedung, waktu pulang-pergi, waktu puncak dan waktu tunggu dalam hal kapasitas (kapasitas pemrosesan) dan kecepatan elevator.(Tanggoro, 2012)

Manajemen pemeliharaan elevator yang baik meliputi pemeliharaan rutin, pemeriksaan komponen, penggantian komponen yang perlu diganti, dan perkiraan biaya tahunan pengelola gedung.(Zayadi and Hp, 2015)

Penelitian ini bertujuan untuk mengetahui jumlah kebutuhan elevator, daya listrik elevator, dan anggaran biaya yang diperlukan untuk perawatan elevator pada Gedung Badan Pengembangan Sumber DayaManusia Kementrian dalam Negeri Jakarta.

\section{Metode Penelitian}

\subsection{Analisis Jumlah Penghuni Gedung}

Analisis jumlah orang yang menempati gedung akan mempengaruhi perhitungan jumlah lift. Peneliti akan menghitung jumlah orang yang tinggal di gedung tersebut berdasarkan data aktual (lapangan) dan perhitungan teoritis penghuni gedung. Perhitungan penghuni gedung dapat dihitung dengan rumus:

$$
\text { Jumlah penghuni }=\frac{\text { luas bangunan }}{\text { luas netto per orang }}
$$

Saat menghitung luas bersih per kapita dari sebuah gedung perkantoran, data teknis yang digunakan untuk memperkirakan jumlah orang yang ditempati oleh gedung tersebut adalah 4 meter persegi per orang.(Poerbo, 1992)

\subsection{Analisis Beban Puncak}

Analisis beban puncak dihitung berdasarkan representasi empiris jumlah penghuni gedung, dan hasil perhitungannya adalah elevator/lift akan mengangkatnya dalam 5 menit pertama waktu puncak. Menurut Poerbo untuk menghitung beban puncak perkantoran dapat dihitung dengan rumus:

$$
P=4 \% \times \text { jumlah penghuni gedung }
$$


Persentasi empiris terhadap jumlah penghuni gedung untuk gedung perkantoran adalah sebesar 4\%. (Poerbo, 1992)

\subsection{Analisis Waktu Tunggu Elevator/Lift}

Waktu tunggu maksimal yang diukur dalam detik, antara pemanggil elevator saat menekan tombol dari lantai dasar /lobby sampai datangnya elevator dan pintu terbuka, waktu tunggu yang disyaratkan untuk gedung perkantoran adalah 25-45 detik.

$$
\begin{gathered}
I=\frac{R T}{N} \\
I=\frac{R T}{\mathbb{N}}
\end{gathered}
$$

Keterangan:

$$
\begin{aligned}
& \mathrm{I}=\text { Waktu } \\
& \mathrm{RT}=\text { Waktu perjalanan bolak-balik } \\
& \mathrm{N}=\text { Jumlah elevator/lift }
\end{aligned}
$$

\subsection{Waktu PerjalananBolakBalik (Round Trip Time)}

Waktu yang dibutuhkan elevator berjalan bolak balik dari lantai terbawah hingga teratas, termasuk waktu berhenti, penumpang keluar masuk elevator, dan pintu membuka dan menutup pada setiap lantai. Waktu perjalanan bolak - balik dapat dihitung dengan rumus:

$$
R T=\frac{(2 h+4 s)(n-1)+s(3 m+4)}{s}
$$

Keterangan

$$
\begin{array}{ll}
\mathrm{RT} & =\text { waktu perjalanan bolak-balik lift/ round trip time (detik) } \\
\mathrm{h} & =\text { tinggi lantai sampai dengan lantai. } \\
\mathrm{s} & =\text { kecepatan rata-rata lantai } \\
\mathrm{n} & =\text { jumlah lantai dalam } 1 \text { zone } \\
\mathrm{m} & =\text { kapasitas lantai }
\end{array}
$$

\subsection{Analisis Jumlah Elevator/Lift}

Jumlah elevator yang memadai akan mempermudah kinerja pengguna gedung untuk berpindah dari satu lantai ke lantai lainnya. Jumlah elevator dapat dihitung dengan rumus:

$$
N=\frac{a^{\prime} n P T}{300 a^{\prime \prime} m}
$$

Keterangan

$$
\begin{aligned}
& \mathrm{N}=\text { Jumlah lift dalam } 1 \text { zone. } \\
& \mathrm{a}=\text { Luas lantai kotor pertingkat. } \\
& \mathrm{P}=\text { Persentasi jumlah penghuni gedung yang diperhitungkan sebagai } \\
& \quad \text { beban puncak lift. } \\
& \mathrm{T}=\text { Waktu perjalanan bolak-balik lift. } \\
& \mathrm{M}=\text { Kapasitas lift. } \\
& \mathrm{a}=\quad \text { Luas lantainetto per orang. } \\
& \mathrm{n}=\text { Jumlahlantaidalam } 1 \text { zone. }
\end{aligned}
$$




\subsection{Daya Listrik Elevator}

Analisis kebutuhan daya Saat menghitung kebutuhan daya elevator, yang harus dicari adalah jumlah elevator yang dibutuhkan dan spesifikasi elevator yang merencanakan untuk mendapatkan daya elevator.(Pramuditya et al., 2012)

Daya yang dibutuhkan untuk satu set lift tergantung pada kapasitas, kecepatan dan jumlah lift. Lift dengan kapasitas $\mathrm{m}$ dan kecepatan s $\mathrm{m} /$ detik memerlukandaya:

$$
E=\frac{0,75 \times m 75 s}{75} H P=0,75 m s w
$$

\subsection{ManajemenPemeliharaan Elevator}

Pemeliharaan adalah Semua tugas rutin dan berulang yang diperlukan untuk memelihara fasilitas (seperti pipa, bangunan, fasilitas penyimpanan, dll.). Dalam kondisi ini, dapat digunakan sesuai dengan kapasitas aslinya atau kapasitas dan efisiensi desain (Badan Standardisasi Nasional, 2011). Mengetahui jenis pemeliharaan elevator yang dilakukan oleh gedung BPSDM KEMENDAGRI Jakarta untuk menjaga keadaan elevator agar tetap berfungsi maksimal. Strategi pemeliharaan menurut (Sharma, A., \& Yadava, 2011):

\section{Breakdown Maintenance}

Breakdown maintenance adalah mengembalikan fungsi peralatan. Tidak ada tindakan yang diambil untuk memahami penyebab kegagalan, atau tindakan apa yang dapat diambil untuk meminimalkan kegagalan di masa mendatang.

2. Preventive Maintenance

Preventive maintenance adalah strategi pemeliharaan yang mengurangi frekuensi dan kegagalan sesekali dengan melakukan perbaikan, penggantian, overhaul, pelumasan, pembersihan, dan inspeksi yang direncanakan pada interval waktu yang ditentukan. Menurut beban kerjanya, pemeliharaan yang dilakukan pada interval pemeliharaan preventif terjadwal biasanya dibagi menjadi empat tingkatan, yaitu: pemeriksaan (I), pemeliharaan minor (R), pemeliharaan sedang (S) dan overhaul (O). Peningkatan beban kerja pemeliharaan dari inspeksi hingga level overhaul.(Asyari Daryus, 2014). Kegiatan pemeliharaan preventif biasanya berupa inspeksi berkala dari masing-masing komponen untuk melihat apakah penyesuaian dan penggantian diperlukan.(Wirdiantoet al., 2020).

\section{Hasil dan Pembahasan}

\subsection{Analisis Jumlah Penghuni Gedung}

Jumlah orang di dalam gedung akan mempengaruhi kalkulasi kebutuhan jumlah elevator. Penghuni gedung harus diperhitungkan secara akurat untuk memenuhi kebutuhan elevator yang dapat mendukung sistem transportasi vertikal dalam gedung. Menghitung jumlah penghuni gedung didasarkan pada teoritis jumlah maksimum penghuni gedung berdasarkan data aktual di lokasi.

$$
\begin{aligned}
\text { Luas netto } & =\text { luas netto }-(\text { luas kotor } x 20 \%) \\
& =3-(3771 \times 20 \%) \\
& =3016,8 \mathrm{~m}^{2}
\end{aligned}
$$


Jumlah maksimal penghuni gedung perlantai $=3016,8: 4 \mathrm{~m}^{2} /$ orang $=754$ orang, jumlah maksimal penghuni Gedung A pada kantor BPSDM KEMENDAGRI adalah 754 orang. Sedangkan untuk gedung F didapat 900 orang, sedangkan berdasarkan data di lapangan jumlah pegawai yang terdapat di gedung A berkisar 480 orang dan gedung $\mathrm{F}$ berkisar 950 orang termasuk tamu apabila auditorium digunakan untuk acara acara tertentu, data tersebut didapat dari hasil wawancara oleh salah satu pegawai bpsdm kemendagri.

\subsection{Beban Puncak Elevator (Peak load)}

Hitung beban puncak berdasarkan pengalaman jumlah penghuni gedung. Beban puncak dihitung yang diangkat oleh elevator dalam 5 menit pertama waktu puncak.Gedung bpsdm kemendagri Jakarta.merupakan gedung perkantoran sehingga didapatkan beban puncak elevator berdasarkan perhitungan teoritis sebagai berikut:

Gedung A

$$
\begin{aligned}
\mathrm{P} & =4 \% \times \text { jumlah penghuni gedung } \\
\mathrm{P} & =4 \% \times 480 \\
& =19,2 \approx 19 \text { orang }
\end{aligned}
$$

Gedung F

$$
\begin{aligned}
\mathrm{P} & =4 \% \text { x jumlah penghuni gedung } \\
\mathrm{P} & =4 \% \times 950 \\
& =38 \text { orang }
\end{aligned}
$$

\subsection{WaktuPerjalananBolak -Balik (Round Trip Time)}

Waktu perjalanan bolak-balik yang dibutuhkan elevator dalam Gedung bpsdm kemendagri jakarta mulai dari lobby hingga tiba di lantai tujuan dan balik ke lobby adalah:

\begin{tabular}{cccc}
\multicolumn{3}{c}{ Tabel 1 Waktu perjalananbolakbalik } \\
\hline No & Nama Gedung & Jumlah elevator & $\begin{array}{c}\text { Waktu } \\
\text { bolakbalik } \\
\text { (detik) }\end{array}$ \\
\hline 1. & Gedung A & 2 & 65,2 \\
\hline 2. & Gedung F & 4 & 92,8 \\
\hline
\end{tabular}

\subsection{Waktu Tunggu}

Waktu tunggu yang diperlukan oleh penghuni untuk dapat diangkut oleh elevator/lift seperti diperlihatkan pada Tabel 2.

Tabel 2 Waktu tunggu

\begin{tabular}{cccc}
\hline \multirow{2}{*}{ No } & Nama Gedung & \multicolumn{1}{c}{ Jam Sibuk } & Waktu Tunggu \\
\hline \multirow{3}{*}{1} & \multirow{2}{*}{ Gedung A } & $07.30-08.30$ & 32,1 \\
\cline { 3 - 4 } & & $11.30-13.00$ & 32,6 \\
\cline { 3 - 4 } 2 & \multirow{3}{*}{ Gedung F } & $15.30-16.00$ & 30,1 \\
\cline { 3 - 4 } & & $11.30-13.00$ & 46,4 \\
\cline { 3 - 4 } & & $15.30-16.00$ & 36.03 \\
\hline
\end{tabular}

Analisis Kebutuhan dan Manajemen Pemeliharaan Elevator Gedung Kementrian Dalam 
Hasil dari perhitungan waktu tunggu standart berdasarkan (Badan Standardisasi Nasional, 2011) untuk gedung ialah 30 - 40 detik. Pada Table 2 dapat dilihat bahwa gedung F memiliki waktu tunggu 46,4 dan hal ini tidak memenuhi syarat.

\subsection{Perhitungan Jumlah Kebutuhan Elevator Gedung F}

Hasil perhitungan untuk jumlah kebutuhan elevator pada gedung $\mathrm{F}$ adalah 4 buah elevator, dengan waktu tunggu 23,2 detik di mana30 $>23,2<40$ detik. Penambahan unit lift digedung $\mathrm{F}$ waktu tunggu yang ada masuk dalam standar SNI dan dapat melayani pengguna lift secara maksimal

Tabel 3 Jumlahkebutuhan elevator gedung F

\begin{tabular}{cccc}
\hline No & Analisis & Aktual & Rencana \\
\hline 1 & Jumlah elevator & 2 & 4 \\
\hline 2 & Waktu bolakbalik & 92,8 & 92.8 \\
\hline 3 & Waktu tunggu & 46.4 & 23.2 \\
\hline
\end{tabular}

\subsection{Daya Listrik Elevator}

Hasil perhitungan dari Table 4 didapat bahwa pada gedung $\mathrm{F}$ apabila direncanakan penambahan 4 unit elevator dari jumlah aktualnya adalah 2 elevator didapat penambahan daya listrik sejumlah $20,9 \mathrm{kwh} / 10$ jam penggunaan dihitung berdasarkan jam operasi harian gedung pada jam kantor.

Tabel 4Biaya penggunaan listrik pada elevator

\begin{tabular}{cccc}
\hline No & Gedung & \multicolumn{2}{c}{ Dayalistrik 10 jam } \\
\hline & & Aktual & Rencana \\
\hline 1 & A & $14 \mathrm{kwh}$ & - \\
\hline 2 & F & $13,6 \mathrm{kwh}$ & $20,9 \mathrm{kwh}$ \\
\hline
\end{tabular}

\subsection{Manajemen Pemeliharaan Elevator}

Metode pemeliharaaan yang diterapkan untuk elevator di gedung bpsdm Kemendagri adalah pemeliharaan preventive. Pemeliharaan dilakukan dengan melakukan pengecekan dan perbaikan kerusakan atas komponen-komponen elevator secara berkala baik harian atau pun per 3 bulan dalam setahun.

Tabel 5 Pengecekan dan perbaikankomponen elevator

\begin{tabular}{llll}
\hline \multicolumn{1}{c}{ Harian } & \multicolumn{2}{c}{ Per-tiga bulan } \\
\hline 1 & $\begin{array}{l}\text { Operator/teknisijalankan elevator } \\
\text { denganmembuka panel power elevator. }\end{array}$ & 1 & $\begin{array}{l}\text { Operator/teknisimemeriksaruangkomput } \\
\text { er, termasuksuhu, catudaya, kebersihan, } \\
\text { dan peneranganruangan. }\end{array}$ \\
\hline 2 & $\begin{array}{l}\text { Operator/teknisiPeriksaarus dan tegangan } \\
\text { pada panel. }\end{array}$ & 2 & $\begin{array}{l}\text { Operator/teknisi periksa pada panel } \\
\text { kontrol (tegangan, gangguan } \\
\text { kesalahan). }\end{array}$ \\
\hline 3 & $\begin{array}{l}\text { Operator/teknisimelakukanpemeriksaante } \\
\text { hadap box panel pada car lift, } \\
\text { kemudianmelakukan setting } \\
\text { tomboluntukmenjalankan lift. }\end{array}$ & 3 & lift. \\
\hline
\end{tabular}


4 Operator/teknisimelakukanpengecekanm obilitas lift denganmenjalankan lift menuju level/lantaitertentu.
4

Operator/teknisimelakukanpemeriksaanr uangluncur lift.

5 Operator/teknisimelaporkankondisi lift pada Biro Umum

5

Operator/teknisimelakukanpemeriksaan

pada hall area, car station,pitarea,alatpendukung.

6 Operator/teknisimembuatlaporanhasilpe meriksaan dan diserahkan pada Sub Bagian dan subbagianmenindaklanjutilaporanhasilpe meriksaan.

\subsection{AnggaranPemelihaan Elevator}

Pemeliharaan terhadap Elevator sangat diperlukan agar Elevator tetap berjalan sesuai fungsi dan kegunaannya. Berikut ini adalah tabel perhitungan anggaran biaya sesuai keadaan aktual dengan acuan harga distributor merk Elevator digunakan pada kantor bpsdm kemendagri. Anggaran ini diperhitungkan dari biaya pemeliharaan yang dilakukan setiap 3 bulan sekali dan pergantian spare part yang dilakukan apabila ada bagian spare part yang harus di ganti.Pemeliharaan yang dilakukan meliputi pengecekan temperature ruang mesin, power supply, kebersihan dan penerangan ruang, Panel control (tegangan, gangguan/error), Mesin lift, ruang luncur lift, Sangkar lift, dan pit area. maupun pergantian spare part dalam satu tahun sesuai dengan jumlah unit elevator yang terdapat di kantor bpsdm kemendagri jakarta, untuk gedung A memiliki 2 unit elevator adalah Rp 11.600.000,00 dan rencana anggaran biaya pemeliharaan untuk gedung $\mathrm{F}$ sesuai perhitungan jumlah elevator yang dibutuhkan yaitu 4 unit adalah Rp 23.630.000,00. diluar biaya Accident

\section{Kesimpulan dan Saran}

\subsection{Kesimpulan}

Berdasarkan perhitungan waktu tunggu untuk gedung $\mathrm{F}$ dengan jumlah elevator sebanyak 2 unit adalah 46,4 detik tidak memenuhi standar yang ditentukan. Sehingga dilakukan perencanaan ulang untuk gedung $\mathrm{F}$ dengan 4 unit lift, waktu tunggu yang didapat adalah 23,2 detik. Daya Listrik yang diperlukan dalam 10 jam untuk kebutuhan elevator dalam masing-masing gedung adalah 14 Kwh untuk gedung A dengan jumlah lift 2 unit dan 20 Kwh dengan jumlah 2 unit untuk gedung $F$. Hasil perhitungan kebutuhan jumlah elevator untuk gedung $F$ kantor bpsdm kemendagri jakarta adalah 4 unit dengan daya $34 \mathrm{Kwh}$

Manajemen pemeliharaan yang diterapkan adalah pemeliharaan preventive di mana pengecekan dilakukan harian dan untuk perawatan dilakukan per 3 bulan dalam satu tahun. Anggaran biaya pemeliharaan yang dilakukan baik itu perawataan maupun pergantian spare part dalam satu tahun sesuai dengan jumlah unit elevator yang terdapat di kantor bpsdm kemendagri jakarta, untuk gedung A memiliki 2 unit elevator adalah Rp 11.600.000,00 dan Gedung F memiliki 2 unit elevator adalah $\mathrm{Rp} 38.615 .000,00$. Rencana anggaran biaya pemeliharaan untuk gedung $\mathrm{F}$ sesuai perhitungan kebutuhan jumlah lift yang dibutuhkan yaitu 4 unit adalah Rp 23.630.000,00. diluar biaya Accident. 


\subsection{Saran}

Saran yang diperlukan untuk penelitian selanjutnya adalah data yang digunakan sebaiknya selengkap mungkin agar tidak menemui kesulitan saat pengerjaannya. Pemeliharaan yang baik dapat menjaga daya guna mesin lebih lama. Peneliti selanjutnya sebaiknya pada saat survei sebaiknya memiliki waktu yang lebih lama agar data lebih akurat.

\section{UcapanTerima Kasih}

Puji syukur kehadirat Allah SWT untuk segalanya. Terima kasih kepada seluruh staf Gedung BPSDM KEMENDAGRI Jakarta yang telah banyak membantu dalam pengambilan data, Terima kasih kepada bapak Dr. Andi Tenrisukki Tenriajeng, MT. Selaku dosen pembimbing dengan sabar memberikan arahan penelitian. Terima kasih juga keluarga besar dan rekan-rekan yang telah membantu menyelesaikan penelitian ini.

\section{Daftar Kepustakaan}

Afifah, A. F. et al. (2017) 'Elevator Pada Gedung Perum Perhutani Unit I Jawa Tengah'.

Asyari Daryus (2014) 'Manajemen Perawatan Preventif Menggunakan Metode Kompleksitas Perbaikan', Rekayasa Teknologi Fakultas Teknik UHAMKA, $1(1)$, pp. 29-33.

Badan Standardisasi Nasional (2011) 'Prosedur Audit Energi', p. 6196.

Frick, H. and Setiawan, P. L. (2002) 'Ilmu Kontruksi Perlengkapan dan Utilitas Bangunan', p. 251.

Moch, G., Balai, I. and Semarang, K. (2014) 'Analisis Sistem Perawatan Lift'.

Poerbo, H. (1992) Utilitas Bangunan. jakarta: Djambatan.

Pramuditya, R. et al. (2012) 'Analisa Perbandingan Biaya Kebutuhan Dan Penggunaan Energi Hotel Yusro Jombang', Teknik ITS, 1(1), pp. 63-66.

Samsudin, wijayanto dan (2013) 'Kenyamanan Lift Bagi Kaum Difable Studi Kasus Di', pp. 90-104.

Sharma, A., \& Yadava, G. S. (2011) 'A Literature review and future perspectives on maintenance optimization. Journal of Quality in Maintenance Engineering', A Literature review and future perspectives on maintenance optimization. Journal of Quality in Maintenance Engineering, pp. 1-4.

Tanggoro, D. (2012) 'Utilitas Bangunan', 66, ע, pp. 37-39.

Wirdianto, E. et al. (2020) 'Model Penjadwalan Pemeliharaan Preventif MesinMesin Produksi untuk Meminimasi Total Tardiness', INVOTEK: Jurnal Inovasi Vokasional dan Teknologi, 20(1), pp. 123-136. doi: 10.24036/invotek.v20i1.629.

Zayadi, A. and Hp, C. (2015) 'Perencanaan Lift Hotel Bertingkat Tiga Puluh Berdasarkan SNI Nomor : 03-6573-2001', 18(November), pp. 131-138. 